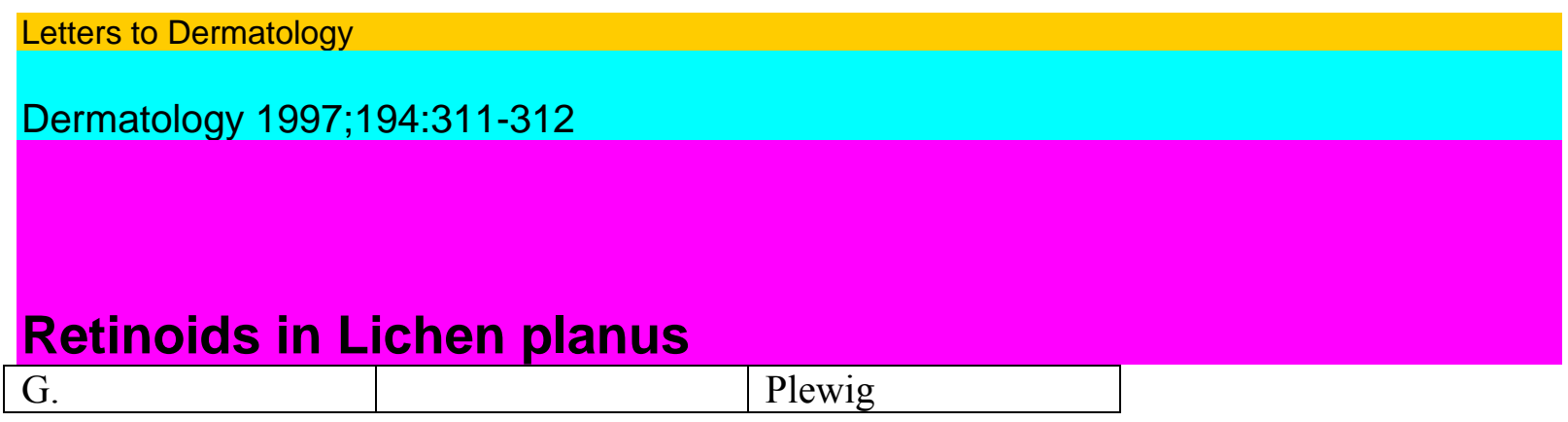

Department of Dermatology, Ludwig Maximilians University, Munich, Germany

Key Words

Retinoids

Tretinoin

all-trans-Retinoic acid

Lichen planus

Gerd Plewig, MD, Department of Dermatology, Ludwig Maximilians University, Frauenlobstrasse 9-11, D-80337 Munich

(Germany)

The interest to use retinoids for the treatment of lichen planus of the skin or oral lichen planus has sporadically appeared in the literature over the past three decades. It is noteworthy that the first mention of this drug family for this condition appeared in 1962 in this journal [ 1 ] (at that time named Dermatologicä).

\title{
Letters to Dermatology
}

311

Six years later, we mentioned our experiences with 13-c/.s-retinoic acid in 11 patients (isotretinoin, RO 4-3780; no commercial product at that time, now Accutane $\AA$, Roaccutan ${ }^{\circ}$ ") and the aromatic retinoid in 16 patients (RO 10-9359, no commercial product at this time; later Tigason $\phi^{\prime}>$ ) for the treatment of oral lichen planus. The dose for 13-c«-retinoic acid ranged from 10 to $60 \mathrm{mg} /$ day. The results were quite encouraging [2].

Now Ott et al. [3], published their experience on the efficacy of oral low-dose tretinoin (all-íra«sretinoic acid) in lichen planus.

Before any further conclusions can be drawn, all-fra«s-retinoic acid, 13-c1/8-retinoic acid, aromatic retinoid and its current replacement, acitretin, should be compared.

Even in the times of modern computer research, publications on the same subject in the samejournal should be presented to the reader, not for the sake of citation but information. References

Beer P: Untersuchungen über die Wirkung der Vitamin-A-Säure. Derma-tologica 1962;124:192195.

Scheiber W, Plewig G: Behandlung des Lichen ruber mucosae mit Vit-amin-A-Säure-Derivaten. Dermatologica 1978;157:171-180.

Ott F, Bollag W, Geiger J-M: Efficacy of oral low-dose tretinoin (•áW-trans-retinoic acid) in lichen planus. Dermatology 1996;192:334-336.

Dermatology 1997; 194:312

Reply

F. Ott, W. Bollag, J.-M. Geiger

Pharmaceuticals Division, F. Hoffmann-La Roche Ltd,

Basel, Switzerland 
Our paper [ 1 ] is a short report on our experience in using low doses of tretinoin (all-?ra«.yretinoic acid) for the treatment of both cutaneous and oral forms of lichen planus. As mentioned by Prof. Plewig, it was first described by Beer [2] in 1962 that systemic tretinoin was beneficial in three skin diseases including Darier's disease, acne and 'érythrodermie ichthyosiforme congénitale'. Since no patients with lichen planus were investigated by Beer, we did not consider it worthwhile to include this reference in our publication.

In a series of publications issued between 1971 and 1975, Günther [3] described the beneficial effect of tretinoin in various forms of lichen planus. To remain concise, we have only cited his last paper, summarizing his previous experience [3].

In 1978, Scheiber and Plewig [4] published their investigations on the efficacy of oral isotretinoin and etretinate in mucosal lichen planus. We would have discussed their interesting results in our paper if this had been a comprehensive review on the general use of retinoids in lichen planus. However, this was not the purpose of our short communication.

We agree with Prof. Plewig that only large-scale clinical trials including comparison with other retinoids will allow to define the exact place of oral tretinoin in the treatment of lichen planus.

References

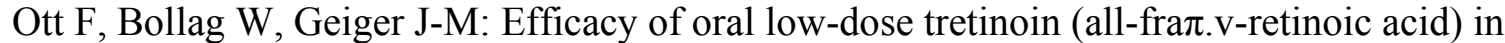
lichen planus. Dermatology 1996;192:334-336.

Beer P: Untersuchungen über die Wirkung der Vitamin-A-Säure. Dermatologica 1962:124:192195.

Günther S: Lichen ruber planus und Lichen ruber verrucosus der Haut: Behandlungsergebnisse mit Vitamin-A-Säure bei 98 Patienten. Z Hautkr 1975;50:59-68.

Scheiber W, Plewig G: Behandlung des Lichen ruber mucosae mit Vit-amin-A-Säure-Derivaten. Dermatologica 1978;157:171-180.

Jean-Marie Geiger,

F. Hoffmann-La Roche Ltd, Pharmaceuticals Division,

CH-4070 Basel (Switzerland)

Announcement

International Society for Dermatologic Surgery: 18th International Congress

The International Society for Dermatologic Surgery's 18th International Congress will be held on September 25-28,1997, at the beautiful old world Grand Hotel Krasnapolsky in Amsterdam, the Netherlands. Topics include: Facial Rejuvenation, Lasers in Dermatology, Phlebology Today, Problem Solving in Dermatologic Surgery, Lipo-suction, Muller Phlebectomy, Hair Restoration, Hair Transplantation, Sclerotherapy, Mohs Micrographic Surgery, Free Communications, For additional information, please contact Sherrie Traficano at the Society headquarters:

International Society for Dermatologic Surgery

930 N Meacham Road

Schaumburg, IL 60173 (USA)

Tel. 8473309830 or fax 8473300050

The 19th Congress of the ISDS will take place from October 30 to

Cutaneous Oncology, General Dermatologic Surgery and Cosmetic November 2, 1998, in Sao

Paulo, Brazil. Further information will be

Dermatologic Surgery. 
available at a later date.

312

Letters to Dermatology 